\title{
TREINAMENTO PROFISSIONAL: NOVAS COMPETÊNCIAS EM INSTITUIÇÕES DE ENSINO PELO USO DA TECNOLOGIA ${ }^{1}$
}

\author{
Valeria Dovgalskaya* \\ Denis Konanchuk** \\ Daniil Dobrynchenko***
}

* Chefe do programa internacional para fortalecer os sistemas de Educação Profissional

(EP) e mercados de trabalho na Comunidade dos Estados Independentes (CEI), na Ásia e no Oriente Médio. Mestrado pela Universidade de Manchester e Mestrado Executivo em Administração de Empresas (EMBA) pela Kingston Business School.

Odintsovo, Moscou, Rússia. E-mail: valeria_dovgalskaya@skolkovo.ru

** Reitor Associado, Professor de Prática e Assessor do Reitor de Projetos Estratégicos na Escola de Administração de Moscou Skolkovo Odintsovo, Moscou, Rússia. E-mail: denis_konanchuk@skolkovo.ru

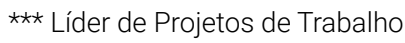
na Escola de Administração de Moscou Skolkovo. E-mail: daniildobr@gmail.com

Recebido para publicação em 6.8.2018

Aprovado em 21.11.2018

\section{Resumo}

O artigo é dirigido, em primeiro lugar, à comunidade de profissionais na área de Educação Profissional (EP) e a empresas e seus representantes, que buscam formatos mutuamente benéficos de cooperação com instituições de ensino. Procura compreender a situação em que os resultados do treinamento são aplicados e investiga as necessidades atuais do mercado, tendo em vista as mudanças tecnológicas que demandam novas competências profissionais para a inovação dos serviços educacionais. Para tanto, analisa projetos aplicados por metodologia própria de uma instituição de ensino russa.

Palavras-chave: Treinamento profissional. Moderação de projetos. Tecnologia. Programas educacionais.

\section{Introdução}

O artigo foi escrito durante a reflexão² do programa Gestão de Mudanças no Sistema EP para o Fortalecimento da Economia Regional (Território de Khabarovsk), da Escola de Gestão Skolkovo de Moscou, no período de março a julho de 2018. O principal objetivo do programa é treinar equipes de gerenciamento de Educação Profissional (EP) no sistema Srednyee Professional'noye Obrazovanie (SPO) ${ }^{3}$, capaz de implementar programas educacionais inovadores para as tarefas de desenvolvimento econômico da região.

O projeto foi implementado no âmbito do Programa Internacional para o Fortalecimento dos Sistemas de Educação Média Profissionalizante e a Promoção do Desenvolvimento dos Mercados de Trabalho na Comunidade dos Estados Independentes (CEI), na Ásia e no Oriente Médio, em cooperação com a Federação da Rússia e a Organização Internacional do Trabalho (OIT).

Para responder à pergunta "Do que a indústria realmente precisa?", é preciso entender que a resposta não é conclusiva e é necessário 
respondê-la de tempos em tempos. Monitorar constantemente os processos de transformação dos mercados torna-se obrigatório para a gestão das instituições de ensino. Só assim é possível que as escolas estejam adequadas à situação real e estabeleçam os requisitos para o resultado e o produto de sua própria atividade. Sem essas análises, as perguntas sobre a transformação da EP, o conteúdo do treinamento e as novas tecnologias educacionais não fazem sentido. Mas aqueles que forem capazes de fazer esse monitoramento se tornarão líderes.

O artigo está organizado da seguinte forma: ele começa com uma justificativa para a necessidade de transformação do sistema EP de uma posição de serviço para superação. O tema da colaboração coletiva entre faculdades e representantes da indústria é considerado em detalhes, com foco na formação de competências tecnológicas exclusivas. A inclusão de escolas EP nesse processo exigirá

As instituições de ensino precisam rever radicalmente o conceito do produto da formação que mudem por si próprias. Segue-se uma descrição detalhada do programa educacional Skolkovo para equipes de gestão da EP, concebido para estabelecer claramente o que as escolas de educação deveriam se tornar e para avaliar as possibilidades de tais mudanças. Antes de chegar às considerações finais, há uma seção descrevendo o método Skolkovo em detalhes. O método Skolkovo permite responder aos desafios e, ao mesmo tempo, desencadear mudanças irreversíveis, neste caso, no campo do ensino profissional.

\section{Agenda da indústria}

A indústria vive um período de transição - a nova revolução industrial está em pleno andamento. Novas tecnologias, às vezes, disruptivas, estão o tempo todo mudando as condições de mercado e, por consequência, a posição das empresas. Os líderes são forçados a correr em velocidade cada vez maior, a fim de, pelo menos, estarem alinhados com as mudanças. Por que isso acontece? É o que analistas e especialistas estão tentando entender (RIFKIN, 2014; SCHWAB, 2017; SHCHEDROVITSKY, 2018). As indústrias tradicionais desaparecerão completamente ou passarão por uma transformação significativa. Surgirão novas indústrias, que provavelmente se tornarão novos líderes.

Assim, as instituições de ensino precisam rever radicalmente o conceito do produto da formação ("A quem vão treinar?"), tanto para indústrias estabelecidas e em transformação como para novas emergentes.

O sistema de treinamento profissional que se consolidou na Rússia e em vários outros países, na sua forma atual, não consegue acompanhar as mudanças pelas quais empresas, organizações e corporações estão passando. Os provedores de educação profissional - escolas de nível médio e superior -, em todos os países, encontram críticas e insatisfação das empresas. Na maioria das vezes, a crítica se deve ao fato de que a preparação é muito longa e, quase sempre, ineficaz. Programas de treinamento longos e ineficazes são produzidos como resul- 
tado da falta de entendimento entre as escolas EP sobre a situação na indústria e dentro das empresas onde profissionais recém-formados começam a trabalhar.

Figura 1 - EP na Rússia em números
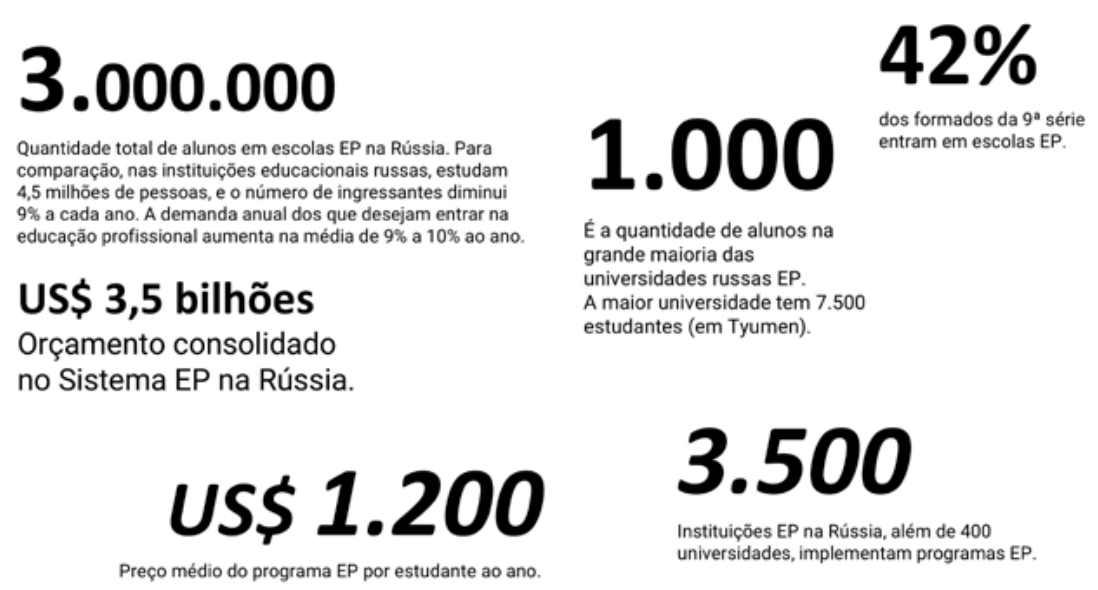

Fonte: Centro de Desenvolvimento Educacional Skolkovo.

A falta de entendimento não se redime nem mesmo pelas previsões do surgimento de novas profissões que surgirão como resultado do progresso tecnológico e quais competências serão requeridas. A própria Skolkovo teve a iniciativa de fazer tais previsões. Publicou o Atlas de novas profissões ${ }^{4}$ descrevendo quais profissões deixarão de existir, quais emergirão e quais habilidades precisarão de treinamento. Mas não funciona assim. O sistema de treinamento que trabalhar dessa maneira será, com alto grau de probabilidade, deficiente e inadequado para o horizonte de desenvolvimento mais próximo da indústria.

A inclusão da Rússia no movimento internacional WorldSkills começou a mudar a opinião pública sobre as profissões técnicas e tornou as escolas EP e seus programas mais atraentes. Muitas das instituições de ensino superior consideravam que, além do sistema campeão graças à WorldSkills, haviam obtido um padrão internacional atualizado para ocupações laborais, e se o país conseguisse reestruturar o sistema de treinamento que prepararia massivamente pessoas no nível das medaIhas conquistadas, as questões de qualidade no treinamento seriam parcialmente removidas. Esse trabalho continua importante e exigirá competências de gestão das instituições de ensino para gerenciar sua própria transformação.

\section{Um novo fator de competitividade}

A questão de trabalho "Em que as escolas de treinamento deveriam prestar atenção para permanecerem relevantes e seus produtos educacionais serem competitivos?" foi formulada durante a reflexão dos programas de treinamento corporativo. Com o que se determina a competitividade nas novas condições? 
A experiência da Skolkovo com corporações e novos negócios sugere que cada empresa está em busca de suas competências exclusivas, as quais são tecnologias ou suas configurações que permitem que ela faça o que nenhuma outra empresa, corporação ou start-up pode fazer. Ao mesmo tempo, o conjunto de competências tecnológicas "obrigatórias" (must have) que as empresas líderes possuem está sendo renovado o tempo todo. E as empresas precisam não apenas ter tais competências, mas também estar preparadas para mudanças com a velocidade que permita permanecer no grupo de líderes de mercado. Com essas competências, a empresa e/ou corporação participa da divisão internacional do trabalho. Um conjunto de competências "obrigatórias" e exclusivas determina o lugar delas na divisão internacional do trabalho: o quanto de alta ou baixa margem, quão promissor ele é.

Por exemplo, em visita à Airbus Defence and Space em 2016, foi ensinada a impressão de uma caixa de satélite em uma impressora 3D. Nenhum dos outros fabricantes de satélites fazia isso na época, era sua competência tecnológica exclusiva. Ela permitiu que eles fizessem um novo design do produto, o que era impossível de produzir em equipamentos antigos. O design especial possibilitou tornar o satélite mais leve e durável, excluir ou reduzir uma série de retrabalhos caros associados aos métodos tradicionais de processamento de metais e não gastar muito dinheiro para sua compra, para produzir um satélite mais rápido. De muitas maneiras, a presença dessa competência, juntamente com a disponibilidade de um conjunto "obrigatório" de competências e boa reputação, permitiu que a empresa recebesse uma solicitação para a criação do primeiro grande satélite serial do mundo para o projeto One Web.

Figura 2 - Níveis de preparação de novas competências técnicas e tecnológicas

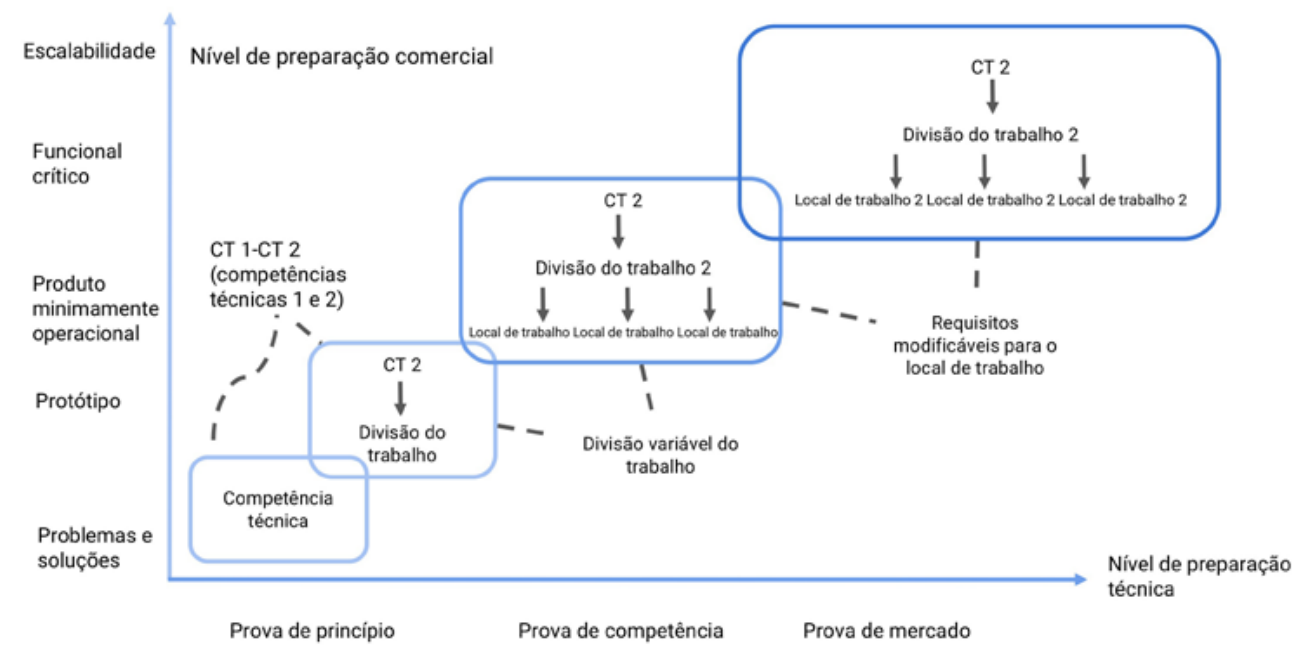

Fonte: Elaborado pelos autores.

Nota: O esquema para o desenvolvimento gradual de competências exclusivas foi formado pelos participantes da Foresight de futuras competências (julho de 2018), realizada pela Escola de Gestão Skolkovo, comissionada pelo Ministério do Trabalho da Federação Russa. As etapas são determinadas pelas escalas de preparação técnica (NPT) e comercial (NPC). 
É necessário entender que cada competência tecnológica está se desenvolvendo. As empresas tentam acompanhar cada estágio do desenvolvimento com o lançamento de um produto com base nesse desenvolvimento, mesmo que a tecnologia não esteja totalmente finalizada. Se for possível implementar pelo menos alguma função que já crie valor para o usuário e cliente, fazem isso e já tornam o produto utilizável. O usuário também é envolvido no desenvolvimento. Analisam a experiência de uso e fazem alterações no produto. Assim, cada lançamento seguinte de um produto em série pode ser diferente do anterior.

É necessário entender que cada competência tecnológica está se desenvolvendo
Isso significa que o desenvolvimento da competência tecnológica passa por certas etapas. Em cada estágio, é necessário criar um novo sistema de divisão do trabalho, um novo conjunto de postos de trabalho, definir novas tarefas e determinar o prazo para alcançá-las. Depois que os parâmetros necessários tiverem sido alcançados, será necessário dividir o trabalho e proporcionar novos empregos e requisitos para as competências pessoais daqueles que vão executá-lo.

Os requisitos para o pessoal e a composição da equipe são determinados a partir das tarefas do estágio específico do desenvolvimento da competência: nova etapa, novas tarefas; nova divisão do trabalho, novos postos de trabalho. Via de regra, parte das pessoas passa do estágio prévio, parte é substituída. Às vezes, é preciso mudar a equipe inteira. Na verdade, cada colaborador está interessado em passar para a próxima etapa, o que significa seu envolvimento no processo de criação de novos postos de trabalho.

No caso anterior da Airbus Defence and Space, também era necessário redefinir os postos de trabalho e a composição da equipe. A empresa conseguiu reduzir a taxa de rejeições com impressão 3D em até $20 \%$. Para a transição para o próximo estágio do desenvolvimento da tecnologia, foi necessário refinar o projeto de engenharia da impressora 3D, continuando o desenvolvimento do pó a partir do qual o produto foi impresso, o que reduziria a taxa de rejeição para 3\% e, nessa tendência, para $0 \%$.

Para garantir essa tarefa, a empresa dedicou cinco anos e assumiu que a equipe consistiria de vários profissionais capazes de trabalhar em uma mesma competência tecnológica.

Por exemplo, eles precisavam de: um químico com certa experiência e conhecimento; um engenheiro encarregado da tarefa de reduzir a rejeição a um mínimo; e um técnico de processo, que resolve simultaneamente os problemas de escalabilidade e integração dessa redistribuição tecnológica na antiga cadeia, bem como a exclusão de algumas antigas redistribuições. Além disso, devido à transição para a produção 3D, os centros de receita e despesa mudaram; portanto, foi introduzida uma posição com um nome antigo, mas com novas funções: o "profissional de marketing", que redesenha o modelo de negócios. 
No processo de transformação digital da produção moderna, na equipe, normalmente, participa o Chief Digital Officer (CDO), que, nesse exemplo, precisava garantir que a impressora 3D estivesse equipada com os sensores necessários, permitindo receber informações e, se necessário, gerenciá-las.

Assim, como afirmado anteriormente, em cada estágio da formação da competência técnica, estão mudando o sistema de divisão do trabalho, o posto de trabalho e os requisitos para as competências pessoais. Para recrutamento de competência tecnológica, é necessário poder montar uma equipe composta por profissionais de diferentes áreas de formação, mas reunidos para tarefas relacionadas a uma mesma competência tecnológica. Também é muito importante prever a expectativa de vida dos locais de trabalho e planejar o desenvolvimento de carreira para cada profissional ou equipe como um todo.

\section{Desafios e oportunidades do sistema EP}

\subsection{Desafio de necessidade}

Em geral, acredita-se que o sistema de ensino profissional prepara uma pessoa para assumir um trabalho específico. Mas, hoje em dia, isso é pouco: é preciso conseguir preparar as pessoas que vão garantir a competência tecnológica da empresa. E isso significa que, além de exercer suas funções diretamente profissionais, terão que se comunicar com outros profissionais que garantam o desenvolvimento e atualização dessa competência. Ao mesmo tempo, também é importante levar em conta que qualquer especialista, ao longo da vida, precisa algumas vezes trocar de trabalho. Mesmo que o objeto de sua atividade continue sendo

É preciso conseguir preparar as pessoas que vão garantir a competência tecnológica da empresa o mesmo (se ele era químico, ele pode continuar sendo químico), terá que mudar de emprego na hora predeterminada. Mas mesmo que ele não mude de emprego, certamente mudará o cargo em si, ou seja, em qualquer caso, ele terá de ser capaz de fazer outra coisa. Isso significa que a EP deve atuar não somente com as competências e qualificações profissionais, mas também com as possíveis trajetórias de carreira, tanto dentro de uma mesma área profissional como além de suas fronteiras.

\subsection{Desafio de eficácia}

Quanto custa um especialista com esse conjunto de competências? Quanto tempo e dinheiro se gasta para o treinamento de tais competências, de modo que seja possível proporcionar postos de trabalho correspondentes para um determinado estágio da vida da tecnologia? Na Rússia, o Estado é responsável por treinar a maioria dos especialistas. Dados produzidos pelo Centro de Desenvolvimento Educacional Skolkovo mostram que o governo gasta uma média de US\$1.200,00, por 
pessoa, por ano, em treinamento e, para algumas especialidades, até US\$ 5.000,00. Para a maioria das faculdades técnicas, o custo do treinamento varia de US\$2.000,00 a US\$ 3.000,00 por ano, com um período de treinamento padrão de quatro anos. Mas o desenvolvimento tecnológico sugere que o fator cada vez mais importante não é nem mesmo o custo de preparação, mas sua precisão e velocidade.

Reduzir o tempo e mudar os formatos educacionais, inevitavelmente, leva ao fato de que o custo da hora de treinamento está aumentando. E isso, ironicamente, é benéfico para todos os participantes do processo, porque aumenta sua eficácia: o mercado de trabalho recebe regularmente especialistas adequados e aumenta-se a concorrência; as empresas recebem funcionários de alto desempenho e a possibilidade de modernização mais agressiva e flexível dos processos de produção; o resultado é uma oportunidade de pagar mais aos representantes do setor educacional a custos totais comparáveis ou até mesmo menores. Os benefícios para os alunos também são óbvios: acesso mais rápido ao mercado de trabalho, aumento da demanda devido à inclusão nos processos de desenvolvimento e modernização tecnológica, obtenção de experiência única e, consequentemente, uma trajetória de carreira mais atraente.

\section{Novas oportunidades para o sistema EP}

No passado, a tarefa do sistema EP era dar ao aluno uma especialidade que seria suficiente por toda a sua vida até sua aposentadoria (possivelmente com um aumento na hierarquia e no nível de responsabilidade, mas, via de regra, tudo na mesma área). No entanto, o sistema deveria estar centrado no aluno e na filosofia de Aprendizado ao Longo da Vida (ALV). O sistema EP deixa de ser apenas um provedor de ensino profissionalizante, para se tornar algo para o qual o estudante pode retornar a qualquer momento. Assim, verifica-se uma mudança de paradigma: o foco agora não é a competência e a qualificação, mas a pessoa em si. A pessoa e sua trajetória de carreira.

As organizações educacionais que escolhem esse caminho demonstram maior competitividade em matéria de capacitação profissional. Os números confirmam: as taxas de matrícula na universidade diminuem em média $9 \%$ ao ano, enquanto o número de estudantes inscritos nas instituições de formação profissional cresce anualmente entre 9 e 10\%. Como utilizar as novas oportunidades emergentes e responder aos novos desafios? 
Figura 3 - Experiência da Skolkovo no âmbito da EP

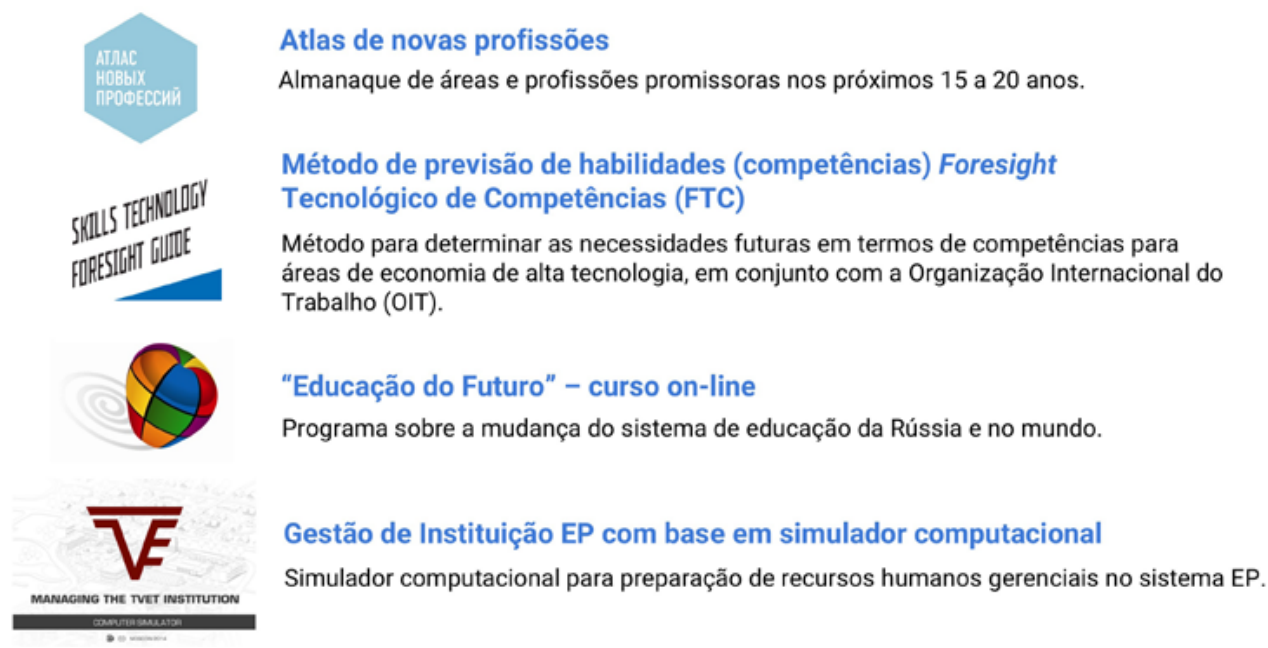

Fonte: Skolkovo website - www.skolkovo.ru.

\section{0 programa internacional de treinamento Gestão de Mudanças no Sistema EP para o Fortalecimento da Economia Regional, um projeto-piloto para o Território de Khabarovsk, na Federação Russa}

A ideia principal do programa era treinar times de gestores para liderarem escolas EP regionais capazes de desenvolverem e implementarem programas educacionais inovadores, que formassem as competências tecnológicas necessárias na região, as quais podem garantir a competitividade dos negócios locais. Mas como realizar isso? É necessário ter uma expertise suficientemente aprofundada nos mercados prioritários, avaliar o potencial de crescimento nesses mercados. É preciso ter experiência suficiente sobre pacotes tecnológicos novos e emergentes que podem fornecer um avanço qualitativo, prever o prazo e as principais tarefas de cada estágio do desenvolvimento do pacote tecnológico e, em cada fase, ter uma versão dos (futuros) postos de trabalho que serão necessários com suas respectivas exigências para a competência dos futuros profissionais. Somente na presença de tal previsão, torna-se possível responder à pergunta sobre de que maneira treinar as pessoas.

O mundo linear entrou em colapso, pois é impossível trabalhar em um sistema no qual um participante do processo - um parceiro comercial ou industrial - determinará o mercado prioritário e, depois, o parceiro de tecnologia ${ }^{5}$ formulará a tarefa técnica para as tecnologias necessárias, desenvolverá tais tecnologias, e então fará um protótipo, para, por fim, montar a linha tecnológica. A gerência determinará quais postos de trabalho precisarão ser criados e formalizará um pedido para a formação de pessoal. Em seguida, a faculdade criará um complexo educacional e metodológico, realizará uma seleção e ensinará por vários anos. 
Hoje em dia, esse sistema não tem mais consistência, tudo acontece em paralelo e todos se influenciam mutuamente. É ainda mais complicado pelo fato de que a situação nos mercados está mudando e as taxas de mercado estão sendo especificadas o tempo todo, alterando os requisitos para tecnologias e especialistas em treinamento. Os planos para o lançamento de novas tecnologias também são desiguais, muitas vezes imprevisíveis, e o surgimento de uma nova tecnologia muda imediatamente a situação nos mercados e altera os requisitos de treinamento.

Uma nova

tecnologia muda

imediatamente

a situação

nos mercados

e altera os

requisitos de

treinamento
Surge, então, uma exigência para as instituições de educação profissional: para manter o ritmo com as mudanças, é necessário ser um participante completo nesse processo, a par dos desenvolvedores de negócios e de tecnologia. No mínimo, isso significa ter sua própria estratégia, entender o valor que a instituição de ensino cria/ pode criar para outros participantes e estar pronto para a mudança. Se, hoje em dia, os impulsionadores do desenvolvimento são uma estratégia de negócios ou inovações tecnológicas, aparecem, então, as perguntas: "O sistema de treinamento de pessoal pode, em alguns casos, ser um impulsionador da mudança?" e "Se sim, como ele deveria ser repensado?"

Tendo formulado essas questões problemáticas, a proposta da Skolkovo foi conduzir um programa educacional para as equipes de gerenciamento das instituições de ensino profissional, que estão interessadas em projetar uma resposta ativa.

\subsection{Principais etapas do trabalho}

Cada etapa do trabalho foi moderada, acompanhada e fornecida com conhecimentos complementares por professores de prática, especialistas especialmente convidados e a equipe da Skolkovo.

No início do programa, foi realizada uma sessão de foresight com o objetivo de prever mudanças tecnológicas e competências exigidas para os setores prioritários do desenvolvimento da economia da região, com o amplo envolvimento de representantes de indústrias, desenvolvedores e fornecedores de soluções tecnológicas, além de representantes de instituições de formação e desenvolvimento. A previsão (foresight) foi levada a cabo tendo em conta as tendências mundiais na transformação de indústrias, mercados e tecnologias.

A seguir, foi realizada uma seleção competitiva de instituições EP que desejam participar do programa. No total, sete equipes foram selecionadas. As equipes de desenvolvimento da EP analisaram cada uma de suas atividades para o desenvolvimento de mercados e cenários para o desenvolvimento de tecnologia. Como resultado, foi formulada a hipótese da aposta estratégica em cada uma das esferas de atividade. A hipótese foi discutida, criticada e esclarecida em diálogo com representantes de empresas regionais, autoridades governamentais, associações de empregadores e instituições de fomento. 
As equipes tiveram que analisar, sob olhar crítico, suas instituições, bem como suas próprias condições, capacidades e ambições. Como resultado, formularam as hipóteses estratégicas do negócio. A hipótese também foi criticada e esclarecida em um diálogo com um parceiro da indústria, um parceiro de tecnologia, bem como representantes de empresas regionais, autoridades governamentais, associações de empregadores e instituições de fomento.

Paralelamente, iniciou-se o trabalho preparatório e prosseguiu-se o desenho dos novos programas educacionais das instituições, ação a qual se tornou o principal tema de cooperação de colégios com parceiros industriais e tecnológicos. O programa lidou com benchmarks russos e internacionais; exemplos dos melhores planos educacionais e seus planos de implementação foram discutidos. A plataforma de negociação foi estabelecida de modo que times gestores discutiram novos programas com seus parceiros e novas parcerias se formaram sob o escopo dos novos programas. As escolas EP começaram a testar elementos individuais e preparar versões-piloto dos programas. Elas começaram a testar elementos individuais dos novos programas desenvolvidos e a trabalhar em versões-piloto funcionais. Do mesmo modo, os participantes dos programas analisaram os resultados de vários estudos sobre habilidades do futuro e novas tecnologias educacionais.

Para o design dos programas de treinamento, que são feitos com base em princípios inovadores, exige-se o recrutamento de novos funcionários e novos recursos, de modo que sempre ocorrem ameaças de representantes da "antiga cultura corporativa da instituição". Para eliminar esses obstáculos, um novo desenho organizacional foi prospectado para suportar a implementação de programas de treinamento inovadores. Somente depois de certificar-se de que todas as condições poderiam ser atendidas, as equipes, com o apoio de parceiros, apresentaram seus projetos para experts, para análise e aprovação, e deram os passos seguintes para sua implementação.

Quadro 1 - Temas dos novos programas inovadores (Território de Khabarovsk)

\begin{tabular}{|l|l|}
\hline Nome & Parceiros \\
\hline Agronomia digital & Maior produtor agrícola da Rússia. \\
\hline Desenho industrial & $\begin{array}{l}\text { Grandes corporações de fabricação de aeronaves e } \\
\text { construção naval. }\end{array}$ \\
\hline Logística transfronteiriça & $\begin{array}{l}\text { Instituições de ensino profissional na China e } \\
\text { empresas de logística russas e chinesas. }\end{array}$ \\
\hline $\begin{array}{l}\text { Administração remota de } \\
\text { automação de mineração }\end{array}$ & Empresas de mineração e universidades russas. \\
\hline
\end{tabular}

(Continua) 
(Continuação)

\begin{tabular}{|l|l|}
\hline $\begin{array}{l}\text { Operador em campo de } \\
\text { complexos de mineração } \\
\text { não tripulados }\end{array}$ & $\begin{array}{l}\text { Empresas de mineração, processamento e } \\
\text { enriquecimento mineral. Empresas que oferecem } \\
\text { tecnologia digital e soluções tecnológicas para } \\
\text { automação e robotização de empresas de mineração. } \\
\text { Faculdades técnicas especializadas da Sibéria e do } \\
\text { Extremo Oriente da Rússia. }\end{array}$ \\
\hline $\begin{array}{l}\text { Tecnologias de engenharia } \\
\text { mecânica moderna }\end{array}$ & $\begin{array}{l}\text { Plantas de construção de máquinas da região em } \\
\text { processo de modernização da produção. Principais } \\
\text { fabricantes mundiais de equipamentos de siderurgia } \\
\text { e soldagem, bem como sistemas de controle de } \\
\text { equipamentos. }\end{array}$ \\
\hline $\begin{array}{l}\text { Soluçães de eficiência } \\
\text { energética em habitação } \\
\text { e utilidades } \\
\text { (água, eletricidade, gás) }\end{array}$ & $\begin{array}{l}\text { Empresas de gestão. Fornecedores de equipamentos } \\
\text { e materiais para o mercado de habitação e serviços de } \\
\text { utilidades. Universidade Regional. }\end{array}$ \\
\hline
\end{tabular}

Fonte: Elaborado pelos autores.

Sete programas-piloto coordenados com parceiros foram programados para serem lançados no outono de 2018. Ao mesmo tempo, a administração regional organizará discussões sobre possibilidades de formar um ecossistema regional que apoie a formação de competências tecnológicas exclusivas no território. Foram anunciados trabalhos sobre o desenvolvimento de mapas necessários no território de competências exclusivas, que envolveram representantes de empresas de tecnologia da região.

\subsection{Conclusões intermediárias}

É possível notar algumas soluções gerais às quais os desenvolvedores dos principais programas de instituições de ensino chegaram:

- A estrutura de competências, elaborada durante o desenvolvimento dos novos programas de treinamento, difere daquela adotada atualmente nas instituições EP. Como regra, além das competências profissionais exigidas para o futuro local de trabalho, essa nova estrutura de competências deve conter competências profissionais generalistas atuais. Além disso, a estrutura deve incluir competências transversais (soft), tais como trabalho em equipe, comunicação, autoeducação, tomada de decisões etc. Também, a nova estrutura de competências dá atenção especial às chamadas "competências corporativas", diretamente relacionadas à cultura corporativa da empresa ou organização, na qual, assume-se, o aluno estará sempre avançando na sua carreira.

- Princípio modular da formação de tais programas: cada módulo possui prazo limitado, focado em uma certa habilidade, capacidade ou conceito. A presença 
de um grande número de módulos efetivos permite a implementação de programas educacionais individuais. Além disso, cada módulo ou uma combinação deles pode ser introduzido pela escola EP no mercado de educação adicional como produto independente, proporcionando sustentabilidade financeira complementar e apoiando a trajetória educacional e profissional de especialistas, implementando o princípio ALV.

- O método dos projetos em equipe é a base para planejar o conteúdo de todos os novos programas. A tipologia e a sequência dos projetos que estão sendo implementados estabelecem os requisitos para o conteúdo acadêmico necessário e o conteúdo prático.

- Os novos programas deveriam fortalecer os laços com parceiros industriais e fornecedores de equipamentos tecnológicos.

- Os estudantes que já estão no curso de treinamento têm a oportunidade de avançar ao longo da carreira da empresa parceira. O sucesso nas atividades do projeto e o sucesso acadêmico afetam diretamente o cargo na prática e a oportunidade de avanço na carreira em treinamento.

- $\quad$ O sistema de divisão do trabalho entre os professores torna-se mais avançado. Novos requisitos para o pessoal das escolas exigem a introdução de novos cargos, como tutor, mentor, gerente de projeto, especialista em tecnologia etc.

- Sem exceção, cada escola EP estabeleceu parcerias com universidades e centros de pesquisa. 0 acesso às pesquisas aplicadas é conhecido como um dos fatores críticos para a formação de competências tecnológicas diferenciadas. De fato, as escolas EP entraram na zona de atividade tradicionalmente ocupada pelo bacharelado aplicado à educação superior.

- Os professores concentram sua atenção nos alunos e em suas trajetórias de aprendizado e carreira. A posição da instituição muda de apenas fornecer às indústrias trabalhadores qualificados para atender aos interesses de toda a vida dos alunos. Assim, atua como assistente no avanço de suas carreiras ao longo da vida. Os alunos voltam às escolas de EP para novas competências em cada nova etapa de suas vidas profissionais.

\subsection{Modelo de trabalho do plano de estudo individual do programa de estudos ${ }^{6}$}

Desenvolvedores de novos programas podem usar esse modelo na qualidade de um esquema especial de organização e atividade que permite planejar programas educacionais junto com os alunos que os cursam. Da discussão anterior, já fica claro que se deve proceder da afırmação: o aprendiz é o sujeito da própria aprendizagem. O modelo (vide Figura 4) contém a lógica descrita na sequência. 
Figura 4 - Novo programa de inovação: modelo do plano individual de aprendizado

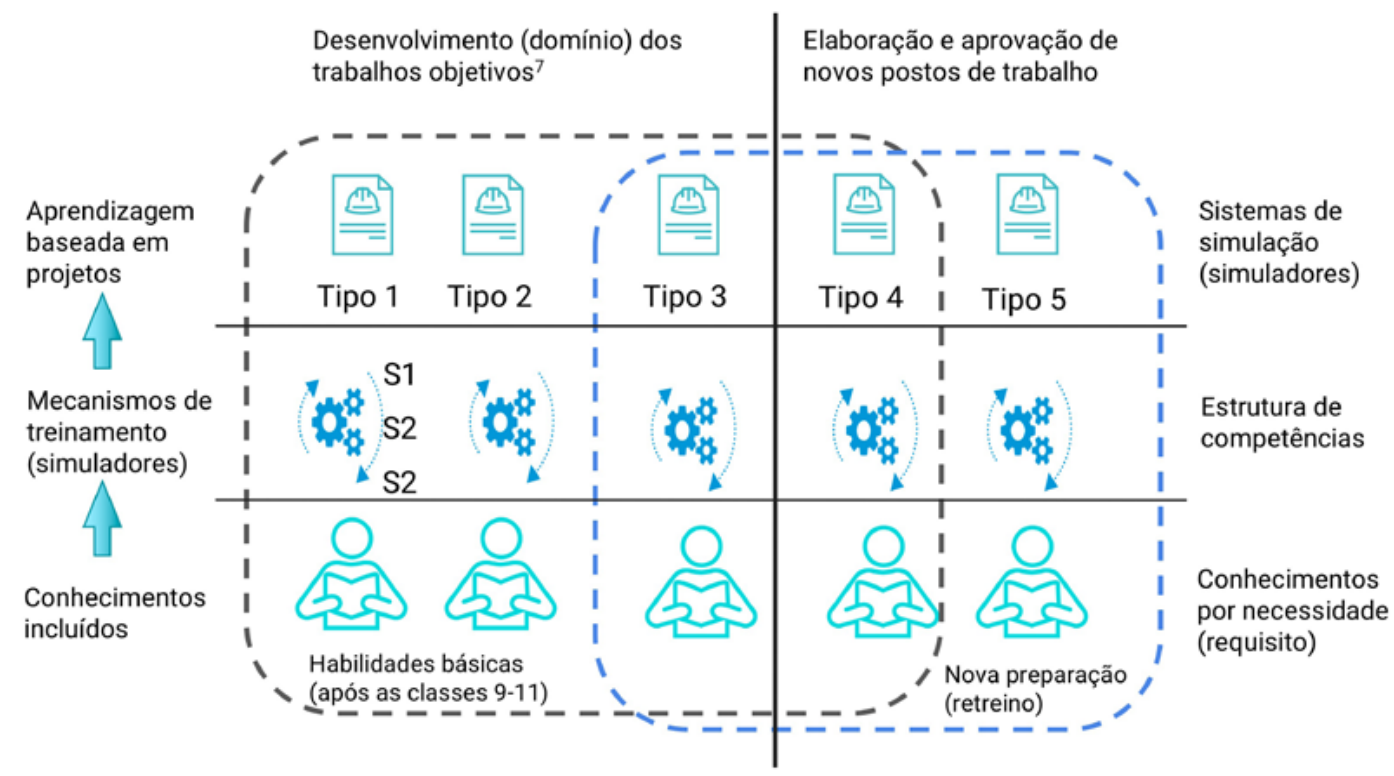

Fonte: Elaborado pelos autores.

O nível básico é o de projetos. Durante a passagem do programa principal, o aluno faz vários trabalhos fora do horário das aulas e projetos-alvo. Cada tipo de trabalho tem seu próprio propósito. Alguns são direcionados ao domínio de instrumentários ou aquisição de habilidades, outros estimulam sua inclusão na inclusão na cultura corporativa e organizacional da empresa. Ainda, há outros que buscarão tornar o produto sob demanda no mercado e sentir a satisfação de produzir algo necessário.

Assim, o novo programa desenvolvido para o desenho industrial pressupõe que o aluno deve consistentemente fazer cinco atividades de pesquisa orientada na cidade onde a escola está localizado o público-alvo, encontrar um problema, desenvolver uma solução técnica, implementar e transferir seus produtos para o usuário final. Utiliza-se como exemplo, um projeto dos alunos da Universidade de Engenharia de Olin (Needham, Massachusetts, Estados Unidos), cujo objetivo é prestar assistência a pessoas com deficiência na resolução de problemas de controle de peso. A presença de uma cadeira de rodas dificulta enormemente esse procedimento. A equipe de alunos projetou balanças nas quais a cadeira possa entrar e criou um aplicativo para dispositivos móveis capaz de considerar o peso dos diferentes tipos de cadeiras. O produto foi entregue ao grupo-alvo e depois passou a ser usado ativamente. Assim, os alunos aprendem a sentir satisfação pelo seu trabalho.

O segundo nível são os simuladores. O domínio das habilidades necessárias é estritamente subordinado ao projeto de trabalho. Em outras palavras, os estudantes desenvolvem habilidades e competências necessárias para a implementação bem-sucedida do projeto desenvolvido. Diferentes tipos de simuladores possibilitam aos 
estudantes dominar a lógica e mecânica dos trabalhos já realizados. A reprodução de determinadas ações forma novas habilidades.

Os conhecimentos e assuntos acadêmicos são usados para fornecer atividades básicas: desenho do programa e, quando necessário, domínio das competências. É importante, primeiramente, formular uma consulta. Isso se chama aprendizado por demanda.

Formar

representações

é uma das

principais

atividades do

treinamento

profissional

Essa pesquisa descobriu uma atitude semelhante em relação às disciplinas educacionais, inclusive, nas escolas da China, onde a camada de trabalhos de design é ocupada por simulações de produção regulares e não regulares, com as quais o aluno se deparará no ambiente de trabalho. Além disso, as situações de produção são divididas em lições e trabalhadas em um modo de simulação por computador. Apenas os conhecimentos e informações necessários são comunicados.

Mas ao contrário do modelo chinês, a pesquisa considerou o estágio-chave do design - o trabalho com representações. A criação de tais representações para os alunos é realizada com a ajuda de professores, representantes de parceiros-mentores industriais, tutores e moderadores, em vez de simplesmente apresentadas aos estudantes. Formar representações é uma das principais atividades do treinamento profissional e é conduzida por procedimentos especiais repetidos em cada estágio do treinamento e reflexão.

O domínio dos trabalhos objetivos, durante o design, deve ser realizado em um formato seguro (por simulação/imitação), na primeira etapa, permitindo que o aluno veja todos os seus erros. Para que os erros sejam traduzidos em conhecimento de atividade, eles devem ser refletidos, isto é, reinterpretados. Esta é a segunda função mais importante da reflexão.

E, finalmente, o ponto-chave desse modelo. Parte dos projetos tem um foco específico: a formação, a aprovação, pode-se dizer, a exploração experimental de novos empregos. Este é o novo produto de novos programas - a capacidade de criar estruturas para novos postos de trabalho para resolução de problemas -, em outras palavras, a capacidade de criar os empregos certos. Isso significa criar tarefas para resolver tarefas correspondentes ao estágio de desenvolvimento de uma competência exclusiva ou obrigatória.

Esse modelo não aborda as questões de interação e envolvimento de parceiros industriais. Essas questões são importantes, porém, estão bem-amadurecidas no modelo de aprendizado dual ${ }^{8}$. O parceiro industrial $l^{9}$ está ativamente envolvido na implementação de projetos, algumas das competências são dominadas com o uso de simuladores das empresas e aplicadas diretamente na produção, algumas solicitações de conhecimento são direcionadas ao parceiro industrial. Além disso, a experiência de envolver empresas no desenvolvimento de novos programas mostrou que as equipes de gestão EP são capazes de cooperar bem próximas aos parcei- 
ros industriais e de facilmente aceitar sua cultura corporativa. Essa cooperação e essa cultura corporativa em comum permitem às escolas EP entregarem soluções significativas para o desenvolvimento de um nível mais alto de aquisição de competências pelas empresas, o que torna essa parceria ainda mais atrativa para as companhias.

\section{Desenvolvendo o método de design}

O método Skolkovo é uma abordagem coletiva, orientada à solução de problemas, altamente engajador e com um grupo grande orientado ao desenvolvimento de questões estruturais, ou, como os experts da Skolkovo gostam de dizer, visam "construir o futuro". É uma "gamificação" no sentido de que o resultado nunca é conhecido antes do final. O método Skolkovo é também chamado de Máquina de Programação do Futuro (SKOLKOVO MOSCOW SCHOOL OF MANAGEMENT, 2018).

O programa educacional para as equipes EP de Khabarovsk foi construído sobre os mesmos princípios básicos sobre os quais a Skolkovo faz seus programas educacionais $^{10}$ - sejam eles para corporações, sejam para autarquias municipais ou regionais, sejam para universidades - , daí a importância em delinear esses princípios.

A Escola Moscovita de Gestão Skolkovo implementa programas de educação empresarial. Como regra geral, os participantes de tais programas são gerentes envolvidos na tomada de decisões estratégicas para o desenvolvimento de uma empresa ou organização. A maioria dos programas da Escola de Gestão Skolkovo é feita em um método de design, o que os torna mais eficientes. $E$, apesar de a Escola de Gestão Skolkovo ser relativamente nova, alguns de seus programas já foram reconhecidos por comunidades profissionais internacionais e receberam prêmios de prestígio.

Figura 5 - Premiações internacionais dos programas Skolkovo, baseados nos métodos ABP

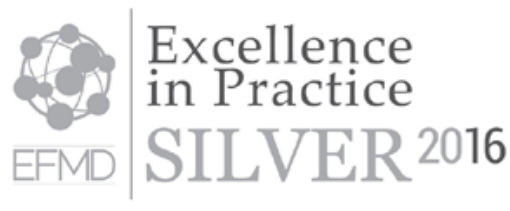

Programa corporativo de desenvolvimento de organizações

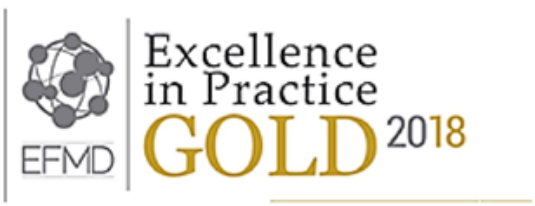

Desenvolvimento do ecossistema

Fonte: www.skolkovo.ru

O método do projeto difere daquele chamado de Aprendizagem Baseada em Projetos (ABP). Embora preserve-se o princípio do objetivo do problema, a primeira diferença está no design. Os educadores mais bem-sucedidos costumam usar o método de projeto no ensino, implementando seu princípio principal como aprender por 
meio de ações (learning-by-doing). Isso é particularmente útil no desenvolvimento de atividades não gerenciais.

A atividade de gerenciamento está associada à identificação do problema principal e à mudança da abordagem do real estado das coisas. Para transformar a atividade em si, a ordem é mudar a opinião e as ideias sobre o assunto do projeto.

O princípio principal do método de projeto praticado na Escola de Gestão Skolkovo é a Aprendizagem por Meio do Desenvolvimento Estratégico. Nessa visão, uma pessoa recebe o maior efeito educacional com sua participação nos processos de desenvolvimento.

Figura 6 - Principal desafio perante a educação de negócios

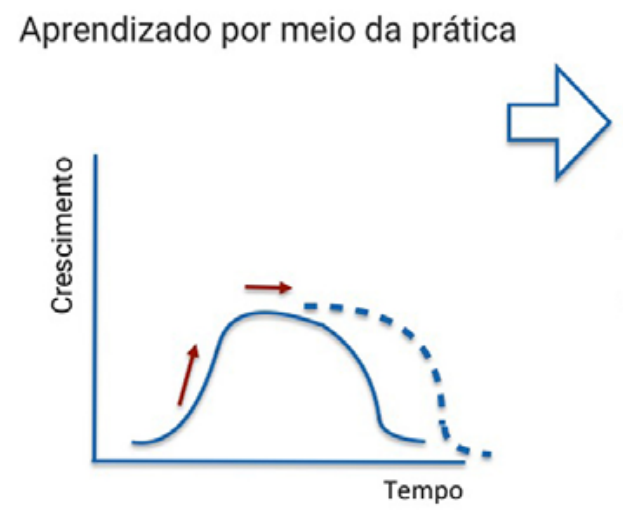

Aprendizado por meio do desenvolvimento

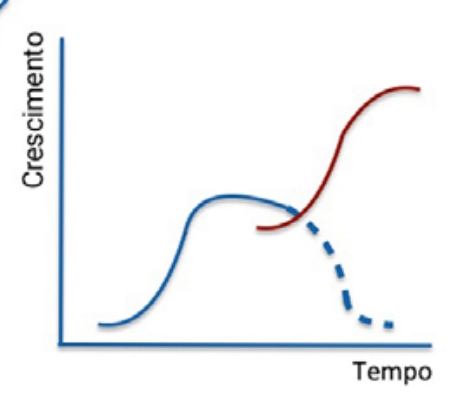

Fonte: Elaborado pelos autores.

Quanto maior a ambição, potencialmente maior o efeito educativo. É necessário levar em conta tais problemas resolvendo o que o próprio profissional ou estudante desenvolve.

A complexidade dos programas da Skolkovo é consequência dessa premissa. Em cada programa no método, lida-se direta e simultaneamente com dois objetos de design: os projetos de desenvolvimento de atividade e o da equipe, que está pronta e em condições para implementar o projeto de desenvolvimento.

Dois assuntos de design requerem esforços bastante significativos. Nesse processo, não está claro quem é o aluno e quem é o professor, o que resulta em uma responsabilidade subsidiária pelo resultado. A qualificação da ideia tem o padrão mais alto - qualquer informação não considerada na fase de elaboração/concepção provavelmente resultará no fracasso da implementação do projeto. De fato, em diferentes estágios, todos participam da mesma equipe, com uma estrutura variável de função e posição. Os moderadores do trabalho do projeto ${ }^{11}$ tornam-se codesigners. Assim, a escola assume sua parcela de responsabilidade pelos projetos implementados por seus ex-alunos. 


\subsection{Projeto de desenvolvimento}

Projeto de

desenvolvimento

estratégico é 0

assunto principal do

método do projeto

Projeto de desenvolvimento estratégico é o assunto principal do método do projeto, pois incorpora a imagem do futuro, o próximo passo no desenvolvimento da empresa e de suas atividades. No caso de um programa educacional para a região de Khabarovsk, equipes de gestores desenharam projetos de desenvolvimento para suas instituições.

As características obrigatórias de projetos de desenvolvimento estratégico são:

- Estratégia: o projeto deve resolver uma tarefa não trivial (em grande escala) da empresa e deve estar alinhado com a estratégia corporativa.

- Subjetividade: o projeto deve exigir que os participantes fiquem incumbidos na sua implementação.

- Problema: cada projeto deve ser destinado a eliminar uma lacuna fundamental no sistema de gestão, que é uma barreira significativa para a implementação da estratégia.

\subsection{Pré-requisitos para aplicar o método de projeto}

Os gerentes precisam se desenvolver ao longo de suas vidas profissionais.

A partir de certo ponto, para o gestor não basta (ou é redundante) melhorar sua qualificação, é necessário desenvolver competências, principalmente no campo do pensamento gerencial.

O horizonte final do pensamento gerencial é pensar ativamente no futuro.

A única maneira de desenvolver o pensamento gerencial é dominar os processos de pensamento necessários e entrar em uma posição gerencial. Isso é possível apenas em atividades práticas, por exemplo, na criação e implementação de um projeto de desenvolvimento.

\subsection{Etapas do projeto de trabalho ${ }^{12}$}

0 trabalho no projeto é realizado em uma determinada ordem. A Figura 7 mostra as principais fases: 
Figura 7 - Etapas do trabalho projetado

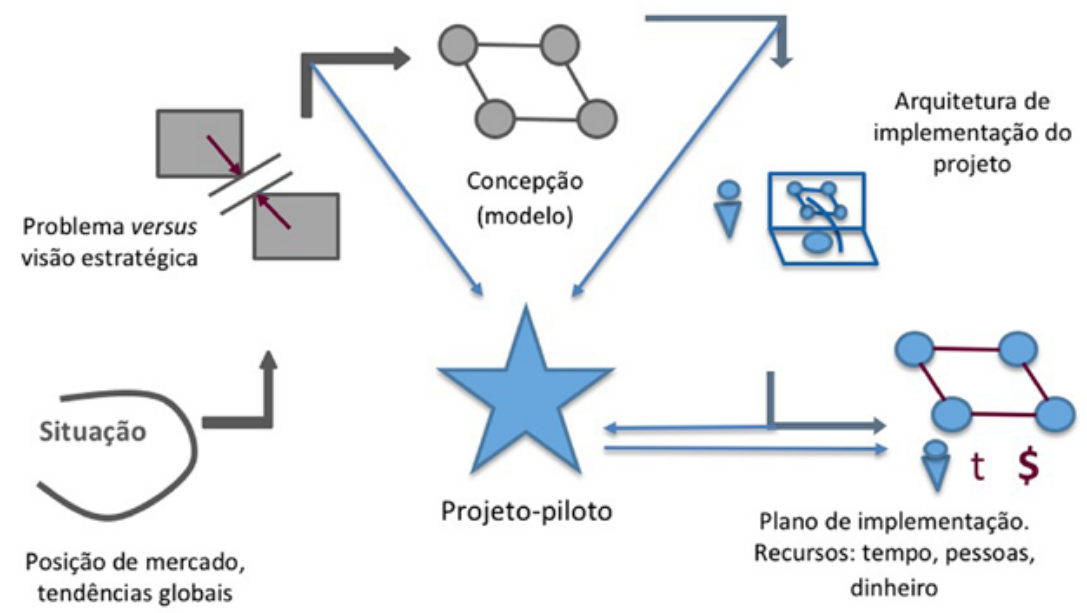

Fonte: Elaborado pelos autores.

Nota: As etapas do projeto de trabalho foram propostas por A. E. Volkov, o primeiro reitor da Escola de Gestão Skolkovo de Moscou. Desde então, elas são a principal tecnologia do método de design. Elas foram ainda refinadas e desenvolvidas por N. S. Verkhovsky e B. M. Ostrovsky.

O trabalho é realizado em dois modos: modular e intermodular. Durante o modo modular, os participantes são completamente envolvidos no projeto de trabalho, sendo afastados das suas funções rotineiras em suas instituições. Durante o modo intermodular, os participantes voltam para suas instituições, mas continuam próximos com os moderadores e experts por meio de diferentes plataformas eletrônicas. No fim de cada módulo, os participantes apresentam seus projetos para uma comunidade de experts composta de gestores e especialistas, recebem feedback sobre a qualidade do projeto e recomendações para seu desenvolvimento, o que eles levarão em conta na fase intermodular.

O desenvolvimento do projeto requer comunicação constante com vários interessados - detentores de tecnologia, experts, potenciais clientes e parceiros. Assim, o trabalho do projeto é transformado de um exercício acadêmico em um trabalho prático, preservando a elaboração teórica e a profundidade mental.

\subsection{Papéis no design do processo}

\subsubsection{Moderador}

Cada grupo lidera seu próprio projeto, e seu trabalho é acompanhado por um moderador, cujas funções são:

- Organização de comunicação efetiva no grupo.

- Fornecimento de ferramentas necessárias de pensamento, design e comunicação ao grupo. 
- Arranjo do esquema de trabalho do grupo e transmissão dos achados mais interessantes do trabalho em grupo no espaço de comunicação de todo o programa educacional.

O moderador é a posição-chave no design. A essência do trabalho dessa posição difere dos moderadores das discussões em conferências. O moderador é, ao mesmo tempo, um engenheiro de projeto, engenheiro social (habilidades interpessoais), coach, planejador, metodologista e, às vezes, um especialista no tópico de um projeto em grupo.

\subsubsection{Curador (patrocinador)}

O trabalho de design visa desenvolver projetos que precisam ser implementados. Para garantir a realização, supõe-se que haja um curador (patrocinador) do projeto que seja integrante da empresa. O curador, em regra, é nomeado pela alta direção da empresa, entre a alta gerência da empresa, sendo usualmente um representante de um gerente sênior - um parceiro industrial.

Funções do curador:

- Sincronizar os objetivos do projeto com os objetivos estratégicos da empresa.

- Examinar e aprovar o projeto com a equipe.

- Proporcionar ao grupo conhecimentos especializados.

- Fornecer os recursos necessários (administrativos, comunicativos, inclusive, a participação na tomada de decisões financeiras) de implementação do projeto.

\subsubsection{Membros da equipe do projeto}

A equipe do projeto consiste de cinco a nove participantes. A equipe do projeto é formada em três fundamentos:

- Competências necessárias para o desenvolvimento e implementação do projeto para o tópico selecionado.

- Capacidade de assumir os papéis necessários para o trabalho em equipe de sucesso em cada estágio (a estrutura de funções pode variar de etapa para etapa).

- $\quad$ Interesse pessoal no sucesso da implementação do projeto.

\subsection{Resultados do programa}

Como resultado, cada grupo que segue os resultados do programa deve ter:

- Tema e composição do grupo definidos e condução da análise da situação sobre o tema.

- Descrição dos objetivos estratégicos no âmbito do tema do grupo, tanto na forma conceitual (visionária) como na forma esboçada (digitalizada). 
- Descrição da situação do problema, aquilo que não permite fazer as mudanças necessárias e alcançar objetivos estratégicos.

- Descrição da ideia do projeto, pela qual seja possível superar a situação do problema.

- Plano de implementação do projeto e seu cronograma, com o mapa dos recursos necessários.

Projetos diferentes no mesmo programa podem implicar um horizonte de tempo diferente para implementação. Parte dos projetos pode ser implementada no momento do programa e, em seguida, são tomados para defesa os resultados imediatos do projeto, descritos como um case. Mas, na maioria das vezes, o projeto requer um longo período de tempo para preparação e lançamento, e os resultados podem ser obtidos em anos. Nesse caso, a equipe do projeto testa a viabilidade em pequena escala e faz um piloto.

Figura 8 - Resultados do programa

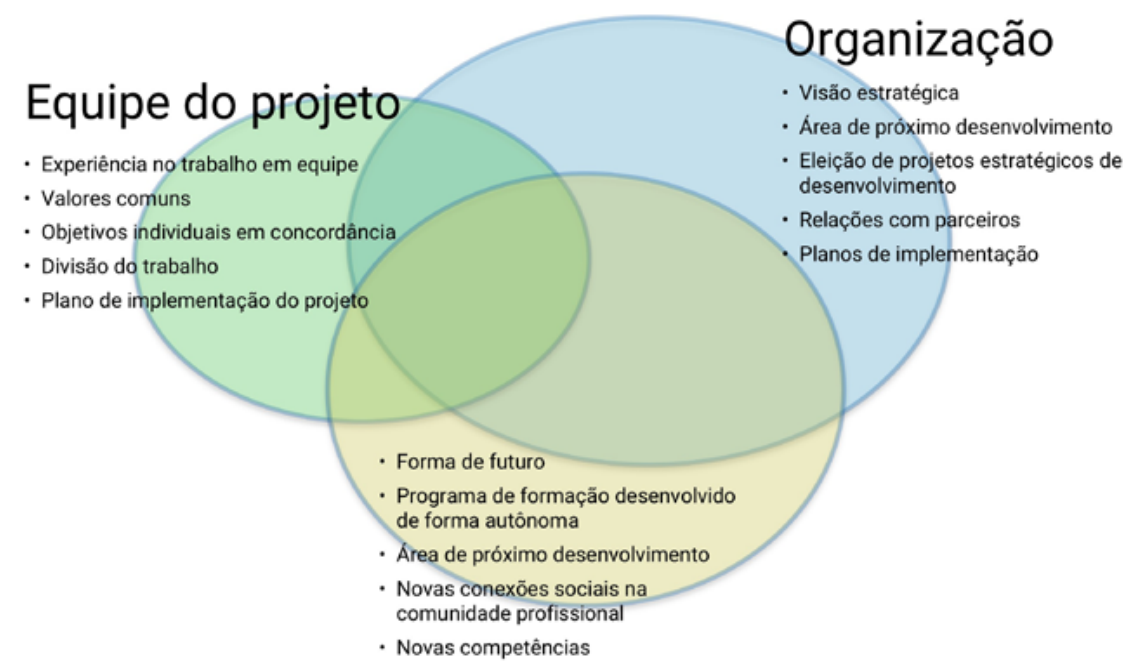

Participante

Fonte: Elaborado pelos autores.

\section{Construção de plano educacional ${ }^{13}$}

O programa consiste de cinco etapas, das quais cada uma representa um módulo completo (cinco dias em período integral) e um período intermodular. 
Figura 9 - Design do programa

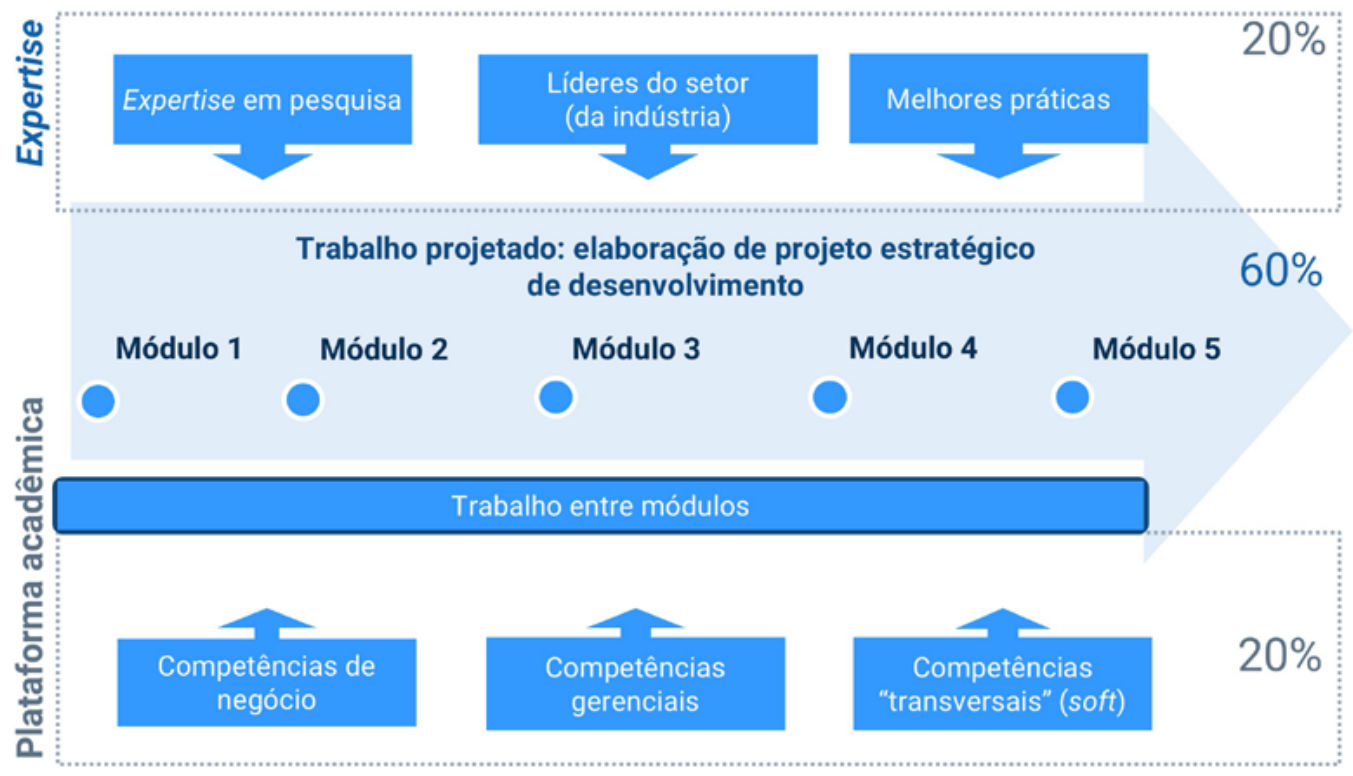

Fonte: Elaborado pelos autores.

Cada módulo termina com uma reflexão dos resultados obtidos e um plano para o trabalho do grupo no período intermodular, quando a equipe de gestores coleta as informações faltantes e conduz negociações com seus parceiros industriais afetados por esse projeto e também comparecem a encontros com especialistas externos e públicos de relacionamento. Uma parte importante do período intermodular é o exame da intenção do projeto, ou seja, se a solução proposta resolve a situação problemática e, ao mesmo tempo, garante a realização dos objetivos estratégicos. No período intermodular, o curador do grupo, geralmente, trabalha próximo à equipe do projeto.

\section{Desenvolvimento adicional do método de design}

No momento, na prática do trabalho de projeto da Escola de Gestão Skolkovo de Moscou, várias direções foram delineadas para a concretização de laboratórios peculiares nos quais são conduzidos experimentos e o método de projeto está sendo desenvolvido. Podem-se destacar as cinco mais promissoras diretrizes implementadas:

- Problematização. Talvez, a parte mais valiosa do método de design. A precisão e profundidade do problema é metade da solução. A capacidade de se problematizar não é tão comum. Os trabalhos sobre o caráter de ganho tecnológico da formulação coletiva do problema foram tratados por G.P. Shchedrovitsky. Nessa direção, há trabalhos de pesquisa, inclusive, bastante atuais. 
- Comunicação posicional. Talvez, o "motor" mais eficaz e promissor do método do projeto. São conduzidos experimentos sobre o ajuste da comunicação posicional nos programas de transformação digital de empresas, gestão universitária, programas de treinamento de empreendedores e o programa de gestão do EP.

- $\quad$ Enfase na exequibilidade (reprodutibilidade efetiva e escalabilidade) dos programas que estão sendo desenvolvidos. É o desenvolvimento tecnológico de etapas individuais do projeto de trabalho nos programas sobre o método e de formatos que proporcionam eficiência. São feitos experimentos com formatos e formas de trabalho. Várias didáticas são desenvolvidas.

- Zona de desenvolvimento proximal. A ideia é que o conceito do projeto que se enquadra na zona do desenvolvimento mais próximo da empresa e dos participantes proporciona o mais poderoso aumento qualitativo a todos. Isso pode ser observado empiricamente. Há uma questão de ferramentas e métodos de trabalho com as zonas do desenvolvimento mais próximas de diferentes participantes e organizações. A própria ideia da zona de desenvolvimento proximal foi formulada por L. S. Vygotsky com referência ao desenvolvimento das crianças. Atualmente, essa ideia funciona também na andragogia e no desenvolvimento estratégico das empresas.

- Preparação de moderadores e gerentes de projeto. Essa direção apareceu com base no aumento da escala de prática e na necessidade de descrever e introduzir padrões profissionais dinâmicos de prática. Trata-se da formação de um departamento profissional. Além disso, há uma discussão importante sobre qual caminho seguir na profissão do moderador.

\section{Figura 10 - Comunidade de alunos formados da Escola de Gestão Skolkovo de Moscou}

\footnotetext{
A Escola Moscovita de Gestão Skolkovo é um centro de projeção do futuro em diferentes esferas de atividades
}

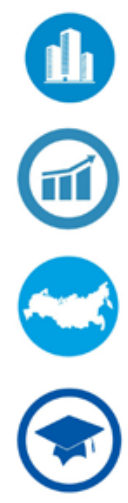

Desenvolvimento de corporações

$>8.900$ alunos formados nos programas corporativos.

Empreendedores, pequeno e médio negócio

$>1.100$ alunos formados nos programas Academia Startup $e$ Oficina para Diretores.

\section{Desenvolvimento de cidades e regiões}

$>1.300$ alunos formados nos programas de desenvolvimento regional, programas para cidades de uma única economia e sessőes estratégicas nas regiőes.

\section{Educação média e superior}

$>1.000$ alunos formados nos programas Escola de Reitores e Gestão de Mudanças no Sistema de Preparação Profissional para Economia de Regiões. 


\section{Considerações finais}

Hoje em dia, os limites entre o ensino profissional secundário e superior são indistintos. Nas condições atuais de rápidas mudanças tecnológicas, o sistema de educação profissional pode e deve ser construído como participante pleno na estratégia de desenvolvimento social e econômico da região. Agora, existe uma oportunidade para as instituições de ensino técnico se afastarem do paradigma usual de serviço, de acordo com o princípio residual, para posicionar-se ativamente no mercado e competir com as universidades.

Para essa transição, as escolas EP devem ter uma estratégia. Isso significa que as instituições de educação profissional deveriam parar de simplesmente atender ao sistema existente de empregos e se comunicar com outras partes interessadas em sua formação. Caso contrário, elas não terão tempo para mudanças e se tornarão irrelevantes.

Na Rússia, via de regra, as instituições EP são consideradas o "irmão mais novo" das universidades, ou para pessoas não muito promissoras. Mas as condições atuais empurram as instituições de educação profissional para a competição no mercado de serviços educacionais e precisam absorver a competência em pesquisa, a competência humanitária. Com isso, escolas EP têm uma série de vantagens competitivas - proximidade às indústrias, natureza aplicada de treinamento, velocidade e custo de treinamento.

Novos programas educacionais são o principal motor de desenvolvimento e novo posicionamento das instituições de educação profissional. A competência para criar novos programas foi amplamente perdida no período pós-soviético. Sob as novas condições, se a instituição de ensino não possuir novidades, ela perderá o seu lugar no mercado, seus recursos e o público-alvo. Voltar às instituições de competência para criar novos programas de treinamento é um fator-chave para o sucesso. Do mesmo modo, como para as demais modalidades de ensino, é importante encarar o desafio associado com o dinamismo de empregos e especialidades relacionadas. O conceito de ALV tem relação mais direta com a educação profissional. A esse respeito, a demanda por competências transversais (soft skills) é significativamente aumentada, e o mercado de programas curtos, rapidamente, se reúne a partir de módulos, como um construtor de Lego, e pode se tornar seu principal mercado. 


\section{Notas}

${ }^{1}$ Os autores agradecem, pela discussão das teses deste artigo, a Andrey Sadakov, moderador do projeto de trabalho da Escola de Gestão Skolkovo de Moscou e seu time: Andrey Volkov, Nikolay Verkhovsky, Olga Nazaikinskaya, Dara Melnik, Andrey Sergeev, Stepan Galushkin, Konstantin Shevchenko, Svetlana Bantos, Anastasia Pyshkina, Mark Mamrykin, Natalya Nikitina, Stepan Galushkin e Zinaida Vorobyeva.

${ }^{2}$ Reflexão significa a revisão após a ação. É a análise da ação realizada, sua eficácia, que está associada à alocação de métodos de ação, sua problematização ou consolidação. É uma ferramenta fundamental para a construção de competências.

${ }^{3}$ É importante notar que, na Rússia, o sistema SPO, que se refere à Educação Profissional de Ensino Médio ou Secundária, realiza-se com base na escola básica (nove anos) e superior. O SPO realiza tanto programas de treinamento de dois a quatro anos como programas curtos, no modo de educação suplementar. O SPO também realiza programas de reciclagem para especialistas.

${ }^{4} \mathrm{O}$ Atlas de novas profissões é um almanaque de promissoras áreas e profissões nos próximos 15 a 20 anos. Consiste em um projeto conjunto da Escola Moscovita de Gestão Skolkovo e da Agência de Iniciativas Estratégicas. Disponível em: $<$ atlas100.ru/en/>

${ }^{5}$ Parceiro de tecnologia é uma empresa, um fabricante ou fornecedor de soluções e equipamentos tecnológicos. A parceria consiste em fornecer às instituições de ensino equipamentos de demonstração, simuladores, programas de treinamento para o trabalho. O parceiro de tecnologia está interessado em trabalhar com as escolas para promover suas tecnologias no mercado.

${ }^{6} \mathrm{O}$ novo programa de inovação fornece posicionamento de mercado e implementação da estratégia da instituição de ensino. Em regra, baseia-se em novas soluções tecnológicas e em um novo pacote de tecnologias educacionais, assegurando a formação de competências exclusivas.

7 Trabalhos objetivos são, no contexto do desenvolvimento de um currículo individual, um tipo especial de organização do treinamento do projeto. Aplicam-se na fase de dominar as habilidades básicas. Ao contrário dos projetos, talvez, não tenham ainda todos os recursos necessários.

${ }^{8}$ A versão em língua russa do método de aprendizado dual está disponível para consulta no site da Agência de Iniciativas Estratégicas: <https://asi.ru/upload/0b6/ Metod_dualeduca-tion_full.pdf>.

${ }_{9}^{9}$ Parceiro industrial é uma empresa ou organização do setor para o qual a instituição de ensino prepara recursos humanos. Na maioria dos casos, o parceiro industrial é um potencial empregador para egressos e fornece vagas para prática e estágio dos estudantes. Do mesmo modo, quando os funcionários da empresa atuam 
como professores, mentores e tutores, os problemas de produção da empresa são objeto de projetos desenvolvidos com os alunos. Como regra geral, o interesse na parceria é confirmado pela existência de relações financeiras.

10 O programa da Escola Moscovita de Gestão Skolkovo baseia-se no método do projeto e na ontologia do desenvolvimento. Uma característica distintiva é que o efeito educacional é alcançado no decorrer do desenvolvimento coletivo de projetos estratégicos, o que pressupõe a coorganização posicional. No núcleo do programa, está o processo de problematização (uma análise da situação que leve a uma identificação qualitativa do problema que o projeto visa resolver).

${ }^{11}$ Gestor de design é o organizador do processo de design no grupo. É responsável pela qualidade da análise da situação e problematização, atua como fonte de problematização dos atuais meios de trabalho em grupo e é fonte de novos recursos, inicia e acompanha o processo de mudança de conceitos e representações no grupo e esquematiza o trabalho do grupo.

${ }^{12}$ As etapas do trabalho do projeto foram propostas por A. E. Volkov, o primeiro reitor da Escola Moscovita de Gestão Skolkovo. Desde então, eles são o núcleo tecnológico do método de projeto. Em seguida, foram refinados e desenvolvidos por N. S. Verkhovsky e B. M. Ostrovsky.

${ }^{13} \mathrm{O}$ projeto do currículo educacional foi originalmente desenvolvido por A. P. Zinchenko, e finalizado por A. E. Volkov e O. L. Nazaykinskaya.

\section{Referências}

Шваб, K. [SCHAWAB, k.]. Четвертая промышленная революция. Москва: $\ni, 2017$.

МОСКОВСКАЯ ШКОЛА УПРАВЛЕНИЯ СКОЛКОВО. Шаг разВИтИЯ школы Московская, 2018. https://sedec.skolkovo.ru/en/sedec/method/?fbclid= IwAR3yfmnw3REmzyRNW5-0FUsUphaFylBzZAgDwdX9aUlku_jFu2eAuJluZAU

Рифкин, Д. [RIFKIN, J.]. Третья промышленная революция: как горизонтальные взаимодействия меняют энергетику, экономику и мир в целом. Москва: АНФ, 2014.

Щедровицкий, Петр [SHCHEDROVITSKY, P.]. Три догоняющие индустриализации России. ХВИЛЯ, 9 jan. 2018. http://hvylya.net/analytics/economics/petr-shhedrovitskiy-tri-dogonyayushhie-industrializatsii-rossii.html 